\title{
BMJ Open Association between perception of fault for the crash and function, return to work and health status 1 year after road traffic injury: a registry-based cohort study
}

\author{
Belinda J Gabbe, ${ }^{1,2}$ Pamela M Simpson, ${ }^{1}$ Peter A Cameron, ${ }^{1,3}$ Christina L Ekegren, ${ }^{1}$ \\ Elton R Edwards, ${ }^{1,4}$ Richard Page, ${ }^{5}$ Susan Liew, ${ }^{4,6}$ Andrew Bucknill, ${ }^{7,8}$ \\ Richard de Steiger 8,9
}

To cite: Gabbe BJ, Simpson PM, Cameron PA, et al. Association between perception of fault for the crash and function, return to work and health status 1 year after road traffic injury: a registry-based cohort study. BMJ Open 2015;5:e009907. doi:10.1136/bmjopen-2015009907

- Prepublication history for this paper is available online. To view these files please visit the journal online (http://dx.doi.org/10.1136/ bmjopen-2015-009907).

Received 5 September 2015 Revised 18 October 2015 Accepted 6 November 2015

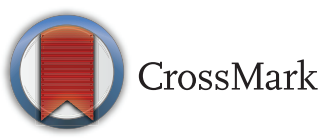

For numbered affiliations see end of article.

Correspondence to Professor Belinda Gabbe; belinda.gabbe@monash.edu

\section{ABSTRACT}

Objectives: To establish the association between the patient's perception of fault for the crash and 12month outcomes after non-fatal road traffic injury.

Setting: Two adult major trauma centres, one regional trauma centre and one metropolitan trauma centre in Victoria, Australia.

Participants: 2605 adult, orthopaedic trauma patients covered by the state's no-fault third party insurer for road traffic injury, injured between September 2010 and February 2014.

Outcome measures: EQ-5D-3L, return to work and functional recovery (Glasgow Outcome ScaleExtended score of upper good recovery) at 12 months postinjury.

Results: After adjusting for key confounders, the adjusted relative risk (ARR) of a functional recovery $(0.57,95 \% \mathrm{Cl} 0.46$ to 0.69$)$ and return to work (0.92, $95 \% \mathrm{Cl} 0.86$ to 0.99 ) were lower for the not at fault compared to the at fault group. The ARR of reporting problems on EQ-5D items was 1.20-1.35 times higher in the not at fault group.

Conclusions: Patients who were not at fault, or denied being at fault despite a police report of fault, experienced poorer outcomes than the at fault group. Attributing fault to others was associated with poorer outcomes. Interventions to improve coping, or to resolve negative feelings from the crash, could facilitate better outcomes in the future.

\section{INTRODUCTION}

Road traffic injury remains a leading cause of death and disability globally. ${ }^{1}$ For every road traffic fatality, a further 20 sustain nonfatal but potentially disabling injuries. These injuries are generally considered unintentional, ${ }^{2}$ although the absence of intent does not preclude attribution of fault or blame for

\section{Strengths and limitations of this study}

Although previous studies have reported external attribution of responsibility for the crash as a reason for why patients do not do well after injury, most studies have been limited to small sample sizes, and reported methodological limitations. This is the largest study to explore the relationship between fault and patient-reported outcomes after injury.

- The capacity to explore the agreement between police and patient-reported fault is unique, patient outcomes were collected at a standardised time postinjury in contrast to previous studies, and the reporting of fault was not collected at the same time as the outcomes.

- Only $71 \%$ of linked claims had a police and patient-reported fault status, and there was loss to follow-up, although this was low (13\%), and there was no evidence of differential follow-up between the fault groups.

- Fault status, rather than blame or responsibility per se, was measured, and as the study was observational, only association was shown and causality cannot be confirmed. The results support the need for the development and testing of strategies for reducing external attribution of responsibility, conflict resolution and improved resilience, as means of reducing the burden of non-fatal road traffic injury.

an injury. External attribution of responsibility for the incident, or blaming others, has been suggested as a reason for why some people do not recover well following injury. It has been hypothesised that blaming others negatively impacts on health due to anger, perceived injustice or victimisation, limiting the capacity to cope following injury or accept what has happened. ${ }^{34}$ 
Despite the potential for external attribution of fault to impact on recovery, the association has not been clearly established. While previous studies have shown these factors to be predictive of poorer physical and mental health outcomes, and greater healthcare utilisation, ${ }^{4-9}$ others have found limited or no association between fault or responsibility and health outcomes in injury populations. ${ }^{10-13}$ Differences in the populations studied, how the participants were recruited, methods for measuring blame or fault, outcomes of interest and the timing of capturing perceptions of blame or fault relative to the injury event, could explain the observed inconsistency of study findings. Furthermore, previous studies have been limited to small sample

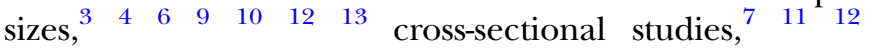
focused on healthcare utilisation only without reference to patient-reported outcomes, ${ }^{5}{ }^{11}$ and none have considered fault from the legal and individual's perspective.

The aims of this study were to quantify the agreement between self-report and police-reported fault status, and to determine the association between fault (self-reported or police-reported) and 12-month patient-reported outcomes, in a cohort of orthopaedic trauma patients admitted to hospital following road traffic injury.

\section{METHODS}

\section{Setting}

Victoria accounts for 27\% (5.8 million) of Australia's population. Victoria's third party, no fault insurer for transport-related injury, the Transport Accident Commission (TAC), is funded through a levy on vehicle registration fees and provides payment for treatment, disability services, income assistance, and other costs. The Victorian Orthopaedic Trauma Outcomes Registry (VOTOR) is a sentinel site registry collecting data from four hospitals in Victoria; two adult level 1 equivalent trauma centres, one regional trauma centre and one metropolitan trauma centre. All adult orthopaedic trauma patients, admitted for greater than $24 \mathrm{~h}$, are included in the registry using an opt-out consent process where all eligible cases are included in the registry, and patients (or their next of kin) are provided with a letter and a brochure stating the aims of the registry, the data collected and any linkage of data, and that patients will be followed-up. The brochure provides the details for how to opt-off and the opt-off rate for VOTOR is $1.5 \%$. At each follow-up interview, verbal consent to complete the interview is obtained. The registry uses an opt-off consent process due to the impracticability of informed consent, and to reduce the potential for selection bias. ${ }^{14}$

\section{Ethics statement}

The registry has been approved by the Human Research Ethics Committee at Monash University and each participating hospital.

\section{Participants}

Cases registered by VOTOR were included in this study if their date of injury was between September 2010 and February 2014, and a valid TAC claim number was provided by the hospital. The timeframe was chosen to correspond with the inclusion of self-reported fault status in the TAC claims database. The TAC has separate claim divisions for catastrophic injury (severe traumatic brain injury and/or spinal cord injury) and less severe injury. The case management, from a compensation perspective, differs according to the claim division. For this reason, severe neurotrauma patients were excluded from the study. The TAC uses Glasgow Coma Scale scores and length of post-traumatic amnesia to define severe traumatic brain injury, while the American Spinal Injury Association (ASIA) Impairment Scale is used to identify patients with significant spinal cord injury. The TAC flag for catastrophic injury was used to identify and exclude these cases.

\section{Procedures}

Demographic, road user group, injury nature and severity, and in-hospital outcomes data were extracted from VOTOR for eligible cases. International Classification of Diseases 10th Revision-Australian modification (ICD-10-AM) diagnosis codes were mapped to the Charlson Comorbidity Index (CCI) to characterise comorbid conditions. ${ }^{15}$ The ICD-10-AM diagnosis codes were also used to classify the nature of orthopaedic injuries sustained and the presence of non-orthopaedic injuries. The patient's residential postcode was mapped to the Accessibility/Remoteness Index of Australia. ${ }^{16}$ Injury severity was dichotomised as major trauma or not major trauma based on the Injury Severity Score (ISS) cut-off of $12 .{ }^{17}$ VOTOR does not directly capture Abbreviated Injury Scale (AIS) data and therefore the ISS is not collected by VOTOR. The ISS data were obtained from the Victorian State Trauma Registry, which collects AIS and ISS data for all major trauma patients in the state of Victoria, to establish whether the VOTOR patients met the ISS $>12$ criterion.

The registry follows up all survivors to hospital discharge by telephone at 6,12 and 24 months postinjury to collect patient-reported outcomes data, ${ }^{18}$ and 12-month outcomes were extracted for this study. The EQ-5D-3 L measures health status using five items (mobility, self-care, usual activities, pain/discomfort and anxiety/depression). ${ }^{19}$ The Glasgow Outcome ScaleExtended (GOS-E) categorises patient function into one of eight categories, with upper good recovery, representing return to preinjury function. ${ }^{20}$ The GOS-E is recommended for use in trauma populations. ${ }^{21}{ }^{22}$ Return to work (yes/no) was collected for patients who reported working for income prior to injury.

Deterministic linkage was used to obtain the policereported and patient-reported fault status from the TAC claims database for eligible cases using the TAC claim number and patient identifiers. No clinical or outcomes 
information from VOTOR was provided to the TAC. Patient and police fault items were used to classify cases into fault status groups. The question asked of police was whether another vehicle was at fault for the crash (yes/no), while the patient was asked whether another person or organisation was at fault for the crash (yes/ no) at the point of claim lodgement. Single vehicle crashes were included and the fault status judged according to the circumstances of the crash. There was no requirement to attribute fault to a vehicle in all cases. Therefore, the police could attribute no fault to the vehicle in single vehicle crashes.

\section{Data analysis}

Agreement between patient-reported and policereported fault was measured using the percentage agreement and the $\kappa$ statistic. $^{23} \chi^{2}$ analyses were used to assess the association between key descriptors of the patient population and fault group. Four fault status groups were used for analysis: (1) patient reported no other person at fault for the crash and police reported that the patient's vehicle was at fault ('at fault'); (2) patient reported no other person at fault for the crash and the police reported that the patient's vehicle was not at fault ('admits fault'); (3) patient reported another person at fault for the crash but police reported the patient's vehicle was at fault ('denies fault'); and (4) patient reported another person at fault and police confirmed that the patient's vehicle was not at fault ('not at fault'). Motor vehicle and motorcycle passengers were categorised in the 'denies fault' group if they attributed fault to another (presumably the driver) despite the police registering their vehicle as at fault for the crash.

The GOS-E was dichotomised for analysis as not recovered versus recovered (GOS-E upper good recovery). For each item of the EQ-5D-3L, the response was dichotomised for analysis into no problems versus problems. Multivariable linear regression was performed to quantify the association between the EQ-5D summary score and fault status. For the GOS-E, return to work and problems on each of the EQ-5D items, the association between fault group and outcome was modelled using modified Poisson regression with a robust variance estimator. ${ }^{24}$ The GOS-E and EQ-5D-3L models were adjusted for key potential confounders including age group, gender, injuries sustained (orthopaedic injury group and the presence of non-orthopaedic injuries), major trauma status, level of education, preinjury work status, road user group, geographic remoteness according to the Accessibility/Remoteness Index of Australia, and the CCI. The return to work model was adjusted for the same factors, except only patients who reported working for income prior to injury were included in the model. Adjusted relative risks (ARR) and the corresponding 95\% CIs are presented for the modified Poisson models, and adjusted mean differences and 95\% CI for the linear model. An interaction between fault group and road user were considered but were not found to be important. Stata V.13(StataCorp, College Station, Texas, USA) was used for all analyses and a $\mathrm{p}$ value less than 0.05 considered significant.

\section{RESULTS}

Agreement between patient and police report of fault status

There were 3666 patients linked and 2605 (71\%) had a patient and police-reported fault status recorded. The group with patient and police-reported fault status was comparable to the remaining $29 \%$ of linked claims. The mean (SD) age of included cases was 43.1 (18.7) years compared to 44.0 (20.2) years in the excluded cases. The proportion of male and major trauma cases was $67 \%$ and $66 \%$ in the included cases, versus $66 \%$ and $59 \%$ in the excluded group, respectively. The profile of road user group was also similar between the included cases (motor vehicle 50\%, motorcycle $28 \%$, pedal cyclist $9 \%$, pedestrian $12 \%$ and other $1.8 \%$ ) and excluded cases (motor vehicle 51\%, motorcycle $25 \%$, pedal cyclist $7 \%$, pedestrian $15 \%$ and other $2.6 \%$ ).

The police and patient were considered to have agreed if the police reported the patient's vehicle at fault and the patient attributed fault to no other person, or vice versa. The percentage agreement between the police and patient reports of fault was $89 \% \quad(\mathrm{n}=2322)$; $91 \%$ for motor vehicle drivers, $85 \%$ for motor vehicle passengers, $89 \%$ for motorcyclists, $90 \%$ for pedal cyclists, $87 \%$ for pedestrians, and $88 \%$ for other transport cases. Where agreement occurred, $50 \%$ of patients were not at fault, though this varied by road user group; $29 \%$ for motor vehicle drivers, $85 \%$ for motor vehicle passengers, $37 \%$ for motorcyclists, $90 \%$ for pedal cyclists, $76 \%$ for pedestrians and $61 \%$ for other transport cases. The $\kappa$ coefficient was 0.78 (95\% CI 0.76 to 0.81 ), indicating 'substantial' agreement between the sources of fault status. ${ }^{23}$ Of the 283 disagreements, 191 (67.5\%) patients reported that another person was at fault for the crash when the police reported that it was the patient's vehicle at fault ('denies fault') (table 1). Of the 2605 included cases, $48 \%$ were single vehicle crashes; $61 \%$ were considered at fault, $30 \%$ considered not at fault, with the remainder split between the disagreement groups.

\section{Overview of patients in each fault group}

There were differences between fault groups for age, injury severity, geographic remoteness, road user group and gender (table 2). Men were more commonly represented in the 'at fault' and 'denies fault' groups. A lower proportion of cases in the 'not at fault' and 'denies fault' groups were major trauma patients, and consistent with this, these groups had a lower proportion of motor vehicle crashes and multiple orthopaedic injuries (table 2). The 'not at fault' and 'denies fault' groups included a higher proportion of clients living in major cities and with a university level of education (table 2). 
Table 1 Comparison of police-reported and patient-reported fault

\begin{tabular}{|c|c|c|c|}
\hline & & \multicolumn{2}{|l|}{ Police report } \\
\hline & & $\begin{array}{l}\text { Patient's } \\
\text { vehicle not } \\
\text { at fault }\end{array}$ & $\begin{array}{l}\text { Patient's } \\
\text { vehicle at } \\
\text { fault }\end{array}$ \\
\hline \multirow[t]{2}{*}{ Patient-report } & $\begin{array}{l}\text { Another person } \\
\text { at fault }\end{array}$ & $1152^{*}$ & $191 \dagger$ \\
\hline & $\begin{array}{l}\text { No other person } \\
\text { at fault }\end{array}$ & $92 \ddagger$ & $1170 \S$ \\
\hline $\begin{array}{l}\text { *Not at fault. } \\
\text { †Denies fault. } \\
\text { †Admits fault. } \\
\text { §At fault. }\end{array}$ & & & \\
\hline
\end{tabular}

A higher proportion of 'not at fault' cases were injured while cycling (table 2). Only $3 \% \quad(n=1)$ of motorcycle passengers, and $4 \%(\mathrm{n}=12)$ of motor vehicle passengers were in the 'denies fault' group.

\section{Functional recovery (GOS-E score upper good recovery)}

At 12 months, $2272(87.2 \%)$ patients had a valid GOS-E score. The proportion of patients who had fully recovered was lower in all other groups compared to the 'at fault' group (table 3). After adjusting for key potential confounders of the relationship between fault status and outcomes, the relative risk of a complete functional recovery was lower for the 'not at fault' and 'denies fault' groups (table 3).

\section{Return to work}

Seventy-one per cent $(n=1841)$ were working prior to injury. Return to work status was known for 1683 (91.4\%) patients at 12 months. The ARR of returning to work was $8 \%$ lower for 'not at fault' patients compared to 'at fault' patients, but was not different for the groups (table 3).

\section{Health status-EQ-5D-3L}

The EQ-5D-3L questionnaire was completed for 2252 (86.4\%) patients at 12 months. The ARR of reporting problems was higher in the 'not at fault' group for the mobility, usual activities, pain or discomfort and anxiety or depression items, (table 3). The 'denies fault' group demonstrated a similar pattern of higher adjusted risk of poorer outcome for the EQ-5D-3L outcomes. The 'admits fault' group experienced higher adjusted risk of poorer EQ-5D-3L outcomes but only for some items (table 3).

\section{DISCUSSION}

Recovery from an orthopaedic injury can be prolonged and complex. Understanding the factors that impact on recovery is needed to identify patients at risk of poorer outcome, and to develop effective strategies and services to reduce the potential for permanent disability.
External attribution of responsibility for the crash or injury event, or blaming others, has been suggested as a reason for why some people do not recover well following injury. ${ }^{7}$ Blaming others may negatively impact on mental health due to anger, perceived injustice or victimisation and limit the capacity for acceptance and recovery following injury. ${ }^{3}{ }^{4}$ In this study of 2605 orthopaedic trauma cases, injured in road traffic accidents, there was agreement between the police report and patient perception of fault in $89 \%$ of cases, and there was a clear pattern of association between fault status and 12-month patient-reported outcomes.

After adjusting for key potential confounders, the group who were not at fault according to the police and the patient, were at higher risk of poorer functional, return to work and health status outcomes when compared to the group where fault for the crash was attributed to the patient (or their vehicle) by the police and the patient. Similarly, patients who considered another person at fault for the crash despite the police determining the patient's vehicle was at fault also demonstrated poorer outcomes. If this group were all motorcycle or motor vehicle passengers, we would expect a similar pattern of association with outcome as the 'not at fault' group. However, only $7 \%$ of this group were motor vehicle or motorcycle passengers, and passenger status was adjusted for in all models. While our observational study was not able to identify reasons for the association, the findings were consistent with previous studies undertaken in road trauma and general injury settings.

Littleton et at studied 193 patients presenting to a single emergency department following a road traffic crash and reported that the group not at fault had poorer mental health in the immediate postcrash period. Similarly, Thompson et $a l^{7}$ in their study of a random sample of 935 TAC claimants, found that external attribution of responsibility was associated with poorer physical and mental health. While Clay et $a l^{4}$ found that external attribution of responsibility was a strong predictor of the presence and severity of pain 6 months after injury. In a study of 30 severely injured patients, blaming others for the crash or injury event was associated with poorer coping, ${ }^{3}$ while a study of 165 motor vehicle crash victims in the USA found that external attribution of responsibility was a risk factor for posttraumatic stress disorder only if the person was the driver of the vehicle involved in the crash. $^{12}$ In our study, the findings were consistent, irrespective of road user group. Trost et a $\hat{l}^{\ominus}$ studied 155 trauma survivors managed at a level 1 trauma centre and found that higher levels of perceived injustice were associated with poorer physical and psychological outcomes 12 months following injury. Almost half of their sample were road traffic injuries but the association was consistent for all injury types. ${ }^{9}$

There were a number of strengths to our study when compared to previous studies. This is the largest study to 
Table 2 Demographics of Victorian Orthopaedic Trauma Outcomes Registry road traffic injury patients stratified by fault status

\begin{tabular}{|c|c|c|c|c|c|}
\hline & $\begin{array}{l}\text { At fault } \\
(n=1170) \\
N(\%)\end{array}$ & $\begin{array}{l}\text { Admits fault } \\
(n=92) \\
N(\%)\end{array}$ & $\begin{array}{l}\text { Denies fault } \\
(n=191) \\
N(\%)\end{array}$ & $\begin{array}{l}\text { Not at fault } \\
(n=1152) \\
N(\%)\end{array}$ & p Value \\
\hline \multicolumn{6}{|l|}{ Gender } \\
\hline Male & $872(74.5)$ & $52(56.5)$ & $129(67.5)$ & $690(59.9)$ & $<0.001$ \\
\hline \multicolumn{6}{|l|}{ Age group (years) } \\
\hline $18-24$ & $278(23.8)$ & $18(19.6)$ & $40(20.9)$ & $173(15.0)$ & $<0.001$ \\
\hline $25-34$ & $223(19.1)$ & $27(29.4)$ & $41(21.5)$ & $231(20.1)$ & \\
\hline $35-44$ & 217 (18.5) & $17(18.5)$ & $43(22.5)$ & $205(17.8)$ & \\
\hline $45-54$ & $168(14.4)$ & $12(13.0)$ & $21(11.0)$ & $198(17.2)$ & \\
\hline $55-64$ & $130(11.1)$ & $6(6.5)$ & $9(4.7)$ & $151(13.1)$ & \\
\hline $65+$ & $154(13.1)$ & $12(13.0)$ & $37(19.4)$ & $194(16.8)$ & \\
\hline \multicolumn{6}{|l|}{ Road user group* } \\
\hline Motor vehicle driver & $619(53.3)$ & $25(27.2)$ & $67(35.1)$ & $260(22.6)$ & $<0.001$ \\
\hline Motor vehicle passenger & 38 (3.3) & 30 (32.6) & $12(6.3)$ & $232(20.2)$ & \\
\hline Motorcycle & 405 (34.8) & $15(16.3)$ & $66(34.5)$ & $234(20.4)$ & \\
\hline Pedestrian & $63(5.4)$ & $15(16.3)$ & $26(13.6)$ & $214(18.6)$ & \\
\hline Pedal cyclist & $21(1.8)$ & $5(5.4)$ & $16(8.4)$ & $185(16.1)$ & \\
\hline Other road transport & $16(1.4)$ & $2(2.2)$ & $4(2.1)$ & $24(2.1)$ & \\
\hline \multicolumn{6}{|l|}{ Geographic remoteness $†$} \\
\hline Major cities & $810(69.3)$ & $62(67.4)$ & 157 (82.2) & 967 (83.9) & $<0.001$ \\
\hline Inner regional & $293(25.1)$ & $23(25.0)$ & 26 (13.6) & $159(13.8)$ & \\
\hline Outer regional/remote & $65(5.6)$ & $7(7.6)$ & $8(4.2)$ & $26(2.3)$ & \\
\hline \multicolumn{6}{|l|}{ Charlson Comorbidity Index condition } \\
\hline Yes & $279(23.8)$ & $13(14.1)$ & $35(18.3)$ & $203(17.6)$ & 0.001 \\
\hline \multicolumn{6}{|l|}{ Orthopaedic injury group } \\
\hline Isolated lower extremity & $214(18.3)$ & $18(19.5)$ & $34(17.8)$ & 267 (23.2) & 0.19 \\
\hline Spinal column injuries only & $243(20.7)$ & $16(17.4)$ & $34(17.8)$ & 237 (20.5) & \\
\hline Isolated upper extremity & $172(14.7)$ & $10(10.9)$ & $28(14.6)$ & $160(13.9)$ & \\
\hline Multiple lower extremity & $125(10.7)$ & $11(12.0)$ & $18(9.4)$ & $92(8.0)$ & \\
\hline Upper and lower extremity & $104(8.9)$ & $8(8.7)$ & 26 (13.6) & $92(8.0)$ & \\
\hline Spine and lower extremity & $88(7.5)$ & $11(11.9)$ & $16(8.4)$ & $86(7.5)$ & \\
\hline Spine and upper extremity & $94(8.0)$ & $8(8.7)$ & $7(3.7)$ & $75(6.5)$ & \\
\hline Spine, upper and lower extremity & $58(5.0)$ & $6(6.5)$ & $16(8.4)$ & $69(6.0)$ & \\
\hline Multiple upper extremity & $49(4.2)$ & $2(2.2)$ & $8(4.2)$ & $45(3.9)$ & \\
\hline Soft tissue injury & $23(2.0)$ & $2(2.2)$ & $4(2.1)$ & $29(2.5)$ & \\
\hline \multicolumn{6}{|l|}{ Associated non-orthopaedic injuries } \\
\hline Head & $92(7.9)$ & $9(9.8)$ & $13(6.8)$ & $90(7.8)$ & 0.85 \\
\hline Chest or abdominal & $486(41.5)$ & $37(40.2)$ & $70(36.6)$ & $442(38.4)$ & 0.35 \\
\hline Other & $328(28.0)$ & $26(28.3)$ & $34(17.8)$ & $263(22.8)$ & 0.001 \\
\hline \multicolumn{6}{|l|}{ Major trauma patient? } \\
\hline Yes & $587(50.2)$ & $48(52.2)$ & $77(40.3)$ & $503(43.7)$ & 0.003 \\
\hline \multicolumn{6}{|l|}{ Level of education $\ddagger$} \\
\hline University degree & $175(16.8)$ & $13(16.2)$ & $40(24.1)$ & $292(29.0)$ & $<0.001$ \\
\hline Advanced diploma or certificate & 390 (37.3) & $24(30.0)$ & 49 (29.5) & $308(30.6)$ & \\
\hline Completed high school & $159(15.2)$ & $16(20.0)$ & $32(19.3)$ & $137(13.6)$ & \\
\hline Did not complete high school/other & $320(30.7)$ & $27(33.8)$ & $45(27.1)$ & $270(26.8)$ & \\
\hline \multicolumn{6}{|l|}{ Working prior to injury? } \\
\hline Yes & $846(77.3)$ & $59(70.2)$ & $125(71.8)$ & $811(74.6)$ & 0.19 \\
\hline
\end{tabular}

explore the relationship between fault and patientreported outcomes after injury. While Elbers et a $\tilde{l}^{2}$ studied 2940 TAC clients, the outcome assessed was healthcare utilisation rather than patient-reported outcomes. The capacity to explore the agreement between police and patient-reported fault is unique and the ratio of at fault to not at fault cases was roughly 1:1. Patient outcomes were collected at a standardised time postinjury in contrast to previous studies, ${ }^{3} 71325$ and the reporting of fault was not collected at the same time as 
Table 3 Association between fault status and orthopaedic injury patient-reported EQ-5D item, GOS-E and return to work outcomes at 12 months postinjury-multivariable analysis results (Victoria, Australia 2010-2014)

\begin{tabular}{|c|c|c|c|c|c|}
\hline Outcome at 12 months & Fault category & $\mathbf{N}$ & $\begin{array}{l}\text { N (\%) with } \\
\text { outcome }\end{array}$ & $\operatorname{ARR}^{\star}(95 \% \mathrm{Cl})$ & p Value \\
\hline \multirow[t]{4}{*}{ Complete functional recovery } & At fault (reference) & 1026 & $246(24.0)$ & 1 & \\
\hline & Admits fault & 81 & $14(17.3)$ & 0.67 (0.39 to 1.14$)$ & 0.14 \\
\hline & Denies fault & 169 & $23(13.6)$ & $0.52(0.35$ to 0.76$)$ & 0.001 \\
\hline & Not at fault & 996 & $160(16.1)$ & 0.57 (0.46 to 0.69$)$ & $<0.001$ \\
\hline \multirow[t]{4}{*}{ Return to work $†$} & At fault (reference) & 780 & $549(70.4)$ & 1 & \\
\hline & Admits fault & 54 & $36(66.7)$ & $1.04(0.86$ to 1.26$)$ & 0.69 \\
\hline & Denies fault & 119 & $83(69.7)$ & $0.93(0.82$ to 1.05$)$ & 0.24 \\
\hline & Not at fault & 730 & $498(68.2)$ & $0.92(0.86$ to 0.99$)$ & 0.03 \\
\hline \multirow[t]{4}{*}{ EQ-5D-3L mobility item } & At fault (reference) & 1016 & 355 (34.9) & 1 & \\
\hline & Admits fault & 79 & $38(48.1)$ & $1.43(1.11$ to 1.83$)$ & 0.01 \\
\hline & Denies fault & 166 & $74(44.6)$ & 1.31 (1.09 to 1.57$)$ & 0.004 \\
\hline & Not at fault & 991 & $436(44.0)$ & 1.39 (1.24 to 1.56$)$ & $<0.001$ \\
\hline \multirow[t]{4}{*}{ EQ-5D-3L self-care item } & At fault (reference) & 1010 & $172(17.0)$ & 1 & \\
\hline & Admits fault & 78 & $20(25.6)$ & 1.41 (0.94 to 2.12$)$ & 0.09 \\
\hline & Denies fault & 165 & $40(24.2)$ & $1.45(1.05$ to 2.01$)$ & 0.02 \\
\hline & Not at fault & 989 & $207(20.9)$ & $1.15(0.93$ to 1.42$)$ & 0.20 \\
\hline \multirow[t]{4}{*}{ EQ-5D-3L usual activities item } & At fault (reference) & 1016 & $536(52.8)$ & 1 & \\
\hline & Admits fault & 79 & $49(62.0)$ & $1.21(1.01$ to 1.45$)$ & 0.04 \\
\hline & Denies fault & 166 & $110(66.3)$ & $1.32(1.16$ to 1.51$)$ & $<0.001$ \\
\hline & Not at fault & 990 & 645 (65.2) & $1.29(1.19$ to 1.40$)$ & $<0.001$ \\
\hline \multirow[t]{4}{*}{ EQ-5D-3L pain or discomfort item } & At fault (reference) & 1003 & $551(54.9)$ & 1 & \\
\hline & Admits fault & 78 & $57(73.1)$ & $1.27(1.09$ to 1.49$)$ & 0.002 \\
\hline & Denies fault & 160 & $102(63.8)$ & $1.20(1.05$ to 1.38$)$ & 0.01 \\
\hline & Not at fault & 975 & $658(67.5)$ & $1.26(1.16$ to 1.36$)$ & $<0.001$ \\
\hline \multirow[t]{5}{*}{ EQ-5D-3L anxiety or depression item } & At fault (reference) & 1015 & $390(38.4)$ & 1 & \\
\hline & Admits fault & 79 & $42(53.2)$ & $1.28(1.02$ to 1.61$)$ & 0.03 \\
\hline & Denies fault & 166 & $79(47.6)$ & $1.31(1.10$ to 1.57$)$ & 0.003 \\
\hline & Not at fault & 985 & $458(46.5)$ & $1.24(1.10$ to 1.40$)$ & 0.001 \\
\hline & Fault category & $\mathbf{N}$ & Mean (SD) & $\begin{array}{l}\text { Adjusted change from } \\
\text { at fault group }\end{array}$ & p Value \\
\hline \multirow[t]{4}{*}{ EQ-5D-3L summary score } & At fault (reference) & 996 & $0.72(0.28)$ & 0 & \\
\hline & Admits fault & 77 & $0.63(0.30)$ & $-0.06(-0.13$ to 0.002$)$ & 0.06 \\
\hline & Denies fault & 159 & $0.66(0.30)$ & $-0.07(-0.12$ to -0.03$)$ & 0.002 \\
\hline & Not at fault & 966 & $0.65(0.30)$ & $-0.09(-0.11$ to -0.06$)$ & $<0.001$ \\
\hline
\end{tabular}

the outcomes. ${ }^{379} 1325$ Nevertheless, there were limitations to the study. Only $71 \%$ of linked claims had a police and patient-reported fault status, although the group where police or patient-reported fault status, but not both, was not different from the included cases. Misclassification is possible, particularly where insufficient or incorrect information was provided to the police at the time of their assessment. There was loss to follow-up, although this was low (13\%), and there was no evidence of differential follow-up between the fault groups. Fault status, rather than blame or responsibility per se, was used and this was collected in a dichotomous way, preventing exploration of the relationship between the degree of perception of fault and outcomes. The study was undertaken within a single jurisdiction with a no-fault compensation system. While studies from fault- based systems have identified a similar association, ${ }^{6} 9$ there may be issues with generalisability of the findings to other jurisdictions. While we could adjust for known differences in the fault groups, other unmeasured confounders may have contributed to the association. Finally, as the study was observational, only association was shown and causality cannot be confirmed.

The findings of this study show that fault status is an important predictor of longer term outcomes following admission to hospital with orthopaedic injuries sustained in road traffic crashes. Patients who were not at fault, or perceived that they were not at fault despite contradictory police reporting, experienced significantly poorer functional, return to work, and health status outcomes at 12 months postinjury. Perceived injustice or victimisation, and anger about the crash, could negatively impact 
on coping skills and the capacity to move on from the crash. Further research could lead to interventions to improve coping and resilience, or resolve the negative feelings associated with the crash, which in turn may lead to better injury outcomes in the future.

\section{Author affiliations}

${ }^{1}$ Department of Epidemiology and Preventive Medicine, Monash University, Melbourne, Victoria, Australia

${ }^{2}$ Farr Institute, Swansea University Medical School, Swansea, Wales, UK ${ }^{3}$ Emergency and Trauma Centre, The Alfred, Melbourne, Victoria, Australia ${ }^{4}$ Department of Orthopaedic Surgery, The Alfred, Melbourne, Victoria, Australia

${ }^{5}$ Department of Orthopaedics, University Hospital Geelong, Geelong, Victoria, Australia

${ }^{6}$ Department of Surgery, Monash University, Melbourne, Victoria, Australia ${ }^{7}$ Department of Orthopaedics, Royal Melbourne Hospital, Melbourne, Victoria, Australia

${ }^{8}$ Department of Surgery, University of Melbourne, Parkville, Victoria, Australia ${ }^{9}$ Epworth Healthcare, Richmond, Victoria, Australia

Acknowledgements The authors thank Melissa Hart, Sue McLellan, Adrian Buzgau, David Attwood and the Steering Committees of VOTOR and the Compensation Research Database (ISCRR) for their assistance with this project.

Contributors BJG participated in conception and design of the study, analysis and interpretation of the data, drafting of the manuscript, critical revision of the manuscript and final approval of the version to be published. BJG also contributed data to the study. PMS participated in the design of the study, analysed the data for the study, contributed to the drafting of the manuscript and gave final approval of the version to be published. PAC provided interpretation of the data, input into the drafting of the manuscript, critical revision of the manuscript and final approval of the version to be published. PAC also contributed data to the study. CLE and RdS provided interpretation of the data, input into the drafting of the manuscript, critical revision of the manuscript and final approval of the version to be published. ERE provided interpretation of the data, input into the drafting of the manuscript, critical revision of the manuscript and final approval of the version to be published. ERE also contributed data to the study. RP provided interpretation of the data, input into the drafting of the manuscript, critical revision of the manuscript and final approval of the version to be published. RP also contributed data to the study. SL provided interpretation of the data, input into the drafting of the manuscript, critical revision of the manuscript and final approval of the version to be published. SL also contributed data to the study. AB provided interpretation of the data, input into the drafting of the manuscript, critical revision of the manuscript and final approval of the version to be published. $A B$ also contributed data to the study.

Funding The Victorian Orthopaedic Trauma Outcomes Registry (VOTOR) is funded by the Transport Accident Commission via the Institute for Safety, Compensation and Recovery Research (ISCRR). BJG and PAC were supported by a National Health and Medical Research Council of Australia Career Development Fellowship (GNT1048731) and Practitioner Fellowship, respectively.

Competing interests None declared.

Ethics approval Monash University, Alfred Health, Northern Health, Barwon Health and Melbourne Health.

Provenance and peer review Not commissioned; externally peer reviewed.

Data sharing statement No additional data are available.

Open Access This is an Open Access article distributed in accordance with the Creative Commons Attribution Non Commercial (CC BY-NC 4.0) license, which permits others to distribute, remix, adapt, build upon this work noncommercially, and license their derivative works on different terms, provided the original work is properly cited and the use is non-commercial. See: http:// creativecommons.org/licenses/by-nc/4.0/

\section{REFERENCES}

1. Global Burden of Disease Study 2013 Collaborators. Global, regional, and national incidence, prevalence, and years lived with disability for 301 acute and chronic diseases and injuries in 188 countries, 1990-2013: a systematic analysis for the Global Burden of Disease Study 2013. Lancet 2015;386:743-800.

2. Norton R, Kobusingye O. Injuries. N Engl J Med 2013;368:1723-30.

3. Bulman R, Wortman C. Attribution of blame and coping in the "Real World": Severe accident victims react to their lot. J Pers Soc Psychol 1977;35:351-63.

4. Clay F, Newstead S, Watson W, et al. Bio-psychosocial determinants of persistent pain 6 months after non-life-threatening acute orthopaedic trauma. J Pain 2010;11:420-30.

5. Elbers N, Collie A, Akkermans A. Does blame impede health recovery after transport accidents? Psychol Inj Law 2015;8:82-7.

6. Littleton S, Hughes D, Poustie $S$, et al. The influence of fault on health in the immediate post-crash period following road traffic crashes. Injury 2012;43:1586-92.

7. Thompson J, Berk M, O'Donnell M, et al. Attributions of responsibility and recovery within a no-fault insurance compensation system. Rehabil Psychol 2014;59:247-55.

8. Thompson J, O'Donnell M, Stafford L, et al. Association between attributions of responsibility for motor vehicle crashes, depressive symptoms, and return to work. Rehabil Psychol 2014;59:376-85.

9. Trost Z, Agtarap S, Scott W, et al. Perceived injustice after traumatic injury: associations with pain, psychological distress, and quality of life outcomes 12 months after injury. Rehabil Psychol 2015;60:213-21.

10. Fitzharris $\mathrm{M}$, Fildes $\mathrm{B}$, Charlton $\mathrm{J}$, et al. The relationship between perceived crash responsibility and post-crash depression. 49th Annual Proceedings of the Association for the Advancement of Automotive Medicine; 12-14 September 2005. Association for the Advancement of Automotive Medicine.

11. Harris I, Young J, Rae H, et al. Predictors of general health after major trauma. J Trauma 2008;64:969-74.

12. Nickerson A, Aderka I, Bryant R, et al. The role of attribution of trauma responsibility in posttraumatic stress disorder following motor vehicle accidents. Depress Anxiety 2013;30:483-8.

13. Waldron B, Benson C, O'Connell A, et al. Health locus of control and attributions of cause and blame in adjustment to spinal cord injury. Spinal Cord 2010;48:598-602.

14. Tu J, Willison D, Silver F, et al. Impracticability of informed consent in the registry of the Canadian Stroke Network. N Engl J Med 2004;350:1414-21.

15. Gabbe B, Magtengaard K, Hannaford A, et al. Is the Charlson Comorbidity Index useful for predicting trauma outcomes? Acad Emerg Med 2005;12:318-21.

16. Care DoHaA. Measuring Remoteness: Accessibility/Remoteness Index of Australia (ARIA). Canberra: Commonwealth of Australia, 2001.

17. Palmer C, Gabbe B, Cameron P. Defining major trauma using the 2008 Abbreviated Injury Scale. Injury 2015. http://dx.doi.org/10.1016/ j.injury.2015.07.003

18. Gabbe B, Sutherland A, Hart M, et al. Population-based capture of long-term functional and quality of life outcomes after major trauma: the experiences of the Victorian State Trauma Registry. J Trauma 2010;69:532-6.

19. Dolan P. Modeling valuations for EuroQol health states. Med Care 1997;35:1095-108.

20. Wilson J, Pettigrew L, Teasdale G. Structured interviews for the Glasgow Outcome Scale and the Extended Glasgow Outcome Scale: guidlines for their use. J Neurotrauma 1998;15:573-85.

21. Sleat G, Ardolino A, Willett K. Outcome measures in major trauma care: a review of current international trauma registry practice. Emerg Med J 2011;28:1008-12.

22. Williamson $\mathrm{O}$, Gabbe B, Sutherland AM, et al. Comparing the responsiveness of functional outcome assessment measures for trauma registries. J Trauma 2011;71:63-8.

23. Landis J, Koch G. The measurement of observer agreement for categorical data. Biometrics 1977;33:159-74.

24. Zou G. A modified poisson regression approach to prospective studies with binary data. Am J Epidemiol 2004;159:702-6.

25. Harris I, Murgatroyd D, Cameron I, et al. The effect of compensation on health care utilisation in a trauma cohort. Med $J$ Aust 2009;190:619-22. 